\title{
A Study on Grey Correlation Degree Model of Venture Capital Intrinsic Value
}

\author{
Linsen Yin \\ Institute of International Finance \\ Shanghai Finance University \\ Shanghai, 201209, China \\ E-mail:yls80@126.com
}

\begin{abstract}
In view of the disfigurement that the former research mostly focus on the evaluation of the investment value before investment, not only this paper uses for reference to the former evaluation system, but also successfully integrates it into a unity that the evaluation before investment and after investment. This paper designs a set of evaluation criterion and a set of actual state evaluation system. Comparing both of them is the essential start of evaluation. Then according to it, and based on the grey correlation degree theory, this paper constructs a set of compositive evaluation index-growth imitating degree, The method provides a primary analysis frame for monitoring venture enterprise fostering.
\end{abstract}

Keywords-venture enterprise; fostering; grey correlation degree; growth imitating degree

\section{INTRODUCTION}

Venture capital is regarded as the motive power to industrialize high technologies. In those European and American developed countries, venture capital has become one of the most accessible financing resources during the process of a venture enterprise's development, and the venture-capital-backed enterprises have also grown into an important part of national economy, which have a profound influence on economy. They enhance the industrialization of high technologies, and so are critical to optimization of the industry structure. Venture capital has accelerated venture firms' growth to a large extent, and cultivated such multinational High-tech corporations as IBM, Intel, Microsoft, Net, yahoo and so on. In the United States, it is venture capital that promotes competition and innovation, and refreshes and energizes American economy.

Presently, researches on venture-capital-investment have kept increasing, and venture-capital-investment has become one of the important problems in the management field. However, a review on previous research results will find no systematic theory on cultivation evaluation and management of venture-capital-investment. Previous research results mostly focus on evaluating the intrinsic value of a venture enterprise, which is the key of how to choose a venture enterprise with high intrinsic value and the first step of a venture enterprise walking to success. But it is not at all. The success of a venture enterprise still needs latterly aborative cultivation from venture capitalist, and the efforts of venture enterprise team. In a word, research about both value evaluation and cultivation to venture enterprises is a systematic engineer, and the neglect or the stagnancy to either research will restricted its development seriously.

In practice, there are plentiful research results about investment value evaluation, but scarcely any about cultivation evaluation. In this way, many venture projects with potential development come to a abortion without the guidance of theories about how to fostering venture capital enterprise. Therefore, the studies about cultivation outcome evaluation conducted in this paper have an important theoretical and practical significance.

\section{INDICATOR SYSTEM DESIGNING}

Researches on venture capital investment began in 1970s. , Wells (1974) and Poindexter (1976) conducted an explorative study on evaluation index for venture capital investment in their doctoral dissertation, which includes firm general criteria (Appropriateness of entrepreneur's background? Business plan sufficiently well advanced? Proprietary business? Investor group satisfactory?) and specific criteria (Size of investment satisfactory? Line of business satisfactory? Stage of development satisfactory? Adequate potential size? Written proposal requirement?). Tyebjee and Bruno (1984) have carried out a telephone survey on a sample of 46 venture capitalists, which including: management skills and history (89\%); market size/growth (50\%); rate of return (46\%); market niche/position (20\%); financial history (11\%); venture location (11\%); growth potential (11\%); barriers to entry (11\%); size of investment (9\%); market/industry expertise (7\%); venture stage (4\%); and stake of entrepreneur (4\%).

Based on an assessment of the concerned technology and product, the indicator system for evaluation of investment in a venture enterprise focuses on team management, and targets at excess financial yields. As an open system, it emphasizes the analysis on the present market and the probability for new technology to create new demand even more, so as to examine comprehensively the venture enterprise's growing potential, environment around it, and various risks involved. Its structure is shown as Figure 1 


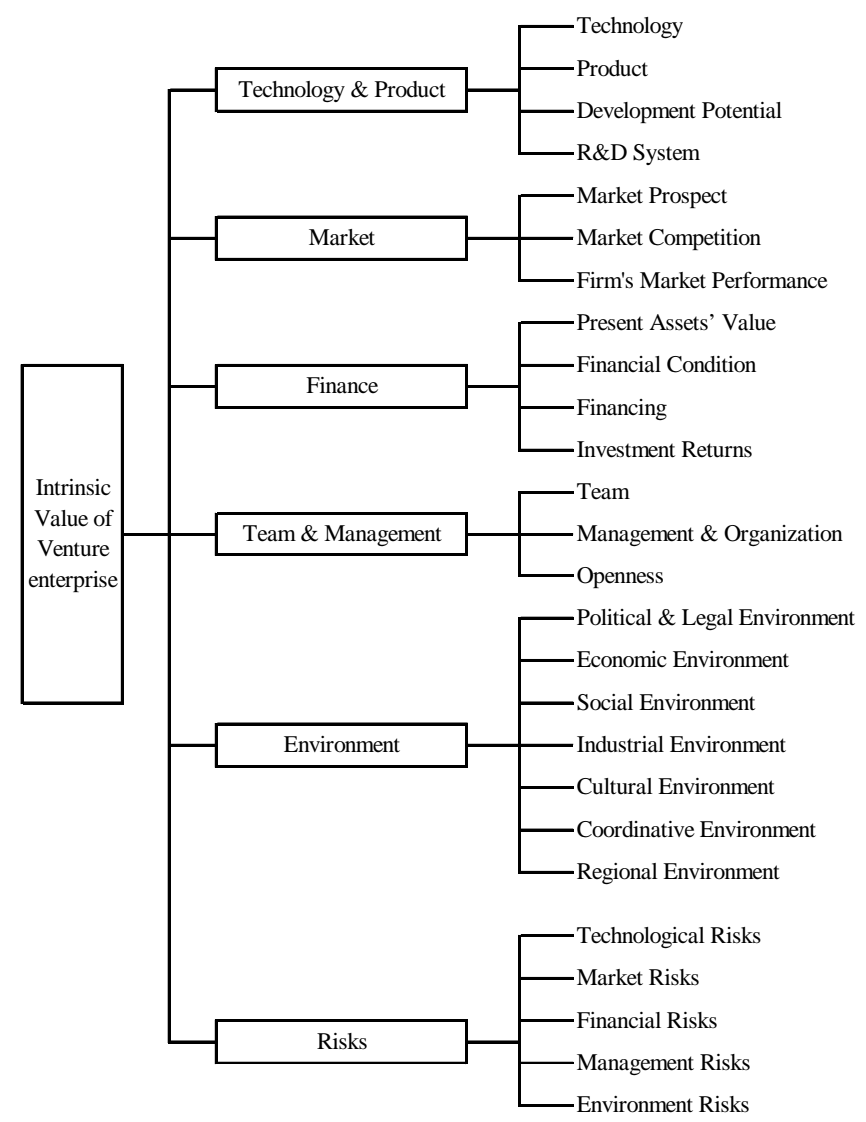

Figure 1. The Overall Structure of the Indicator System for Evaluation of Investment in a Venture Enterprise

\section{VENTURE ENTERPRISES FOSTERING GROWTH IMITATING DEGREE MODEL}

\section{A. Methodology}

Research about cultivation evaluation can use for reference of evaluation system of intrinsic investment value. This is also why we review the former literature and conclude the overall structure of the indicator system. Reference the above indicator system, we expect to construct the like method to evaluate cultivation outcome.

The basic research thought is:

First using Delphi expert grade method, ask expert design a set of reasonable evaluation criterion to correlate factors (in figure 1), which is perfect state that venture enterprise should seek. Second, evaluate the realistic cultivation conditions contrast to the perfect state and acquire respect grade matrix. Third, deal with these data matrix using mathematic tool and conceive quantitative model to evaluate cultivation outcome.

In view of barren research about cultivation outcome, the studies conducted in this paper try to bring forward a set of analysis frame, and base on it construct evaluation model for monitoring the fostering condition, in order to make up blankness in field of venture capital.

Correlation analysis of grey system focuses on quantitative analysis to dynamic development process of a system. The method is to compare correlation degree based on alike or alien degree during dynamic development process. The fundamental thought is to compare correlation degree between the evaluation object and perfect object. More close both of them are, bigger the correlation degree is. In mathematics, call this degree Grey Correlation Degree.

The primary research about Grey Correlation Degree mostly focuses on time serial analysis and deal with stochastic variable. Latterly mathematics science proves that the thought can make derivative research about transverse aspect or sectional data. That is, by mapping from original data to transverse one to compare all influence factors in each state of system, Grey Correlation Degree can describe the relation of all factors.

The thought is conducted to research about cultivation outcome evaluation in the paper. We regard cultivation outcome evaluation as a system, regard technology and product, market, finance, team and management, environment, risks as six subsystems, and design a set of indicator system. Then invite $k$ experts to confirm evaluation criterion (perfect state) and grade value to all subsystem and their corresponding factors, and next ask these $k$ experts compare all influence factors indicating cultivation outcome with the evaluation criterion confirmed by them. Thus it gives us a set of data matrix for evaluation cultivation outcome. In model, we will compare a set of data from each expert based on the evaluation criterion, which gives $k$ evaluation numerical value. In order to avoid the limitation from experts' cognition, we sum up the $k$ evaluation numerical value by weight. The result integrates all information from cognition by mathematics tool and has a new meaning. We define the result as fostering growth imitating degree for venture enterprise.

\section{B. Procedure}

Evaluation procedure and imitating degree model

\section{1) Grading by experts}

Adopt Delphi expert grading method.

First experts confirm grade criterion and respective grade rank (assume 10 grade rank, and define rank 1 as the best rank). Second referring to grade criterion, evaluate all influence factors of venture enterprise being cultivated, and get corresponding grade factor matrix. Just as the follow matrix:

$$
g_{i}=\left[\begin{array}{llll}
g_{i 01} & g_{i 02} & \cdots & g_{i 0 n} \\
g_{i 11} & g_{i 12} & & g_{i 1 n} \\
g_{i 21} & g_{i 22} & & g_{i 2 n} \\
& & \cdots & \\
g_{i k 1} & g_{i k 2} & & g_{i k n}
\end{array}\right]
$$


Notice: $i$ is subsystem $i, k$ is expert $k, n$ is factor $n$. The first row vector $g_{i 0}$ is the frame of reference. In model, we only deal with system with 3 hierarchies.

The other subsystems are in accordance with the matrix above.

\section{2) Dealing with data matrix}

Comparing $g_{i 1}, g_{i 2}, \ldots, g_{i k}$ with the frame of reference $g_{i 0}$, get a new analysis matrix $L_{i}$.

$$
L_{i}=\left[\begin{array}{cccc}
\frac{g_{i 01}}{g_{i 01}} & \frac{g_{i 02}}{g_{i 02}} & \cdots & \frac{g_{i 0 n}}{g_{i 0 n}} \\
\frac{g_{i 11}}{g_{i 01}} & \frac{g_{i 12}}{g_{i 02}} & \cdots & \frac{g_{i 1 n}}{g_{i 02}} \\
\frac{g_{i 21}}{g_{i 01}} & \frac{g_{i 22}}{g_{i 02}} & \cdots & \frac{g_{i 2 n}}{g_{i 0 n}} \\
\frac{g_{i k 1}}{g_{i 01}} & \frac{g_{i k 2}}{g_{i 02}} & \cdots & \frac{g_{i k n}}{g_{i 0 n}}
\end{array}\right]=\left[\begin{array}{cccc}
L_{i 01} & L_{i 02} & \cdots & L_{i 0 n} \\
L_{i 11} & L_{i 12} & \cdots & L_{i 1 n} \\
L_{i 21} & L_{i 22} & \cdots & L_{i 2 n} \\
& & \vdots & \\
L_{i k 1} & L_{i k 2} & \cdots & L_{i k n}
\end{array}\right]
$$

3) Dealing with parameters

Comparing with ${ }^{L_{i 0}}, L_{i k}$ difference series is $\varphi_{i 0 k}$.

$\varphi_{i 0 k 1}=\left|L_{i 01}-L_{i k 1}\right|, \quad \varphi_{i 0 k 2}=\left|L_{i 02}-L_{i k 2}\right|, \ldots$,

$\varphi_{i 0 k n}=\left|L_{i 0 n}-L_{i k n}\right|$

The collection of difference series is $\varphi_{i o k}^{t}$ $\left(\varphi_{i 0 k 1}, \varphi_{i 0 k 2}, \cdots, \varphi_{i 0 k n}\right)$

According to the method, comparing $L_{i 0}, L_{i 1}, L_{i 2} \ldots$ with $L_{i 0}$, difference series are $\varphi_{i 01}, \varphi_{i 02} \ldots$.

Extremum parameter

$$
\begin{aligned}
& \varphi_{i 0 k}(\max )=\max _{k} \max _{n} \varphi_{i 0 k n}, \\
& \varphi_{i 0 k}(\min )=\operatorname{minmin}_{n} \varphi_{i 0 k n}
\end{aligned}
$$

Differentiation coefficient $\gamma$ lies in a range $(0,1)$.Popularly define $\gamma=0.5$

The formula of grey correlation coefficient is

$$
r_{i o k n}\left(L_{i o n}, L_{i k n}\right)=\frac{\varphi_{i 0 k}(\min )+\gamma \varphi_{i 0 k}(\max )}{\varphi_{i 0 k n}+\gamma \varphi_{i 0 k}(\max )}
$$

\section{4) Conforming weight}

In evaluation process, weight conforming is a key. There are various methods in calculating weight value, which is mostly based on subjective or external angle. As our evaluating model is to synthetically analyze subjective expert grades, it is reasonable to calculating weight value from subjective thoughts. AHP(Analytical Hierarchy Process) is a useful method in multi-criteria decision making problems. It consists of three parts: the hierarchy structure, the matrix of pairwise comparisons, and the method for calculating the priorities. Since relative measurements called "pairwise comparisons" are based on human intuition and experts' experience, the AHP can reflect a decision maker's attitude in actual decision problem. In view of AHP subjective characteristics, it is a good method to calculating weight value. The process of AHP sees Appendix 1.

Using AHP, we respectively calculate all factor weights

$w_{i n}$ and all subsystem weights $w_{i}$.

5) Imitating degree model

The formula $r_{i o k}\left(L_{i o}, L_{i k}\right)$ is

$r_{i o k}\left(L_{i o}, L_{i k}\right)=\sum_{n} \cdot r_{i o k n}\left(L_{i o n}, L_{i k n}\right)$

We regard $r_{i o k}\left(L_{i o}, L_{i k}\right)$ as grey correlation degree , Where $n=1,2, \cdots$, is variable, $i, k$ is subsystem $i$ and expert $k$ 。

Grey correlation degree $r_{i o k}\left(L_{i o}, L_{i k}\right)$ indicates grey imitating degree that expert $k$ compares actual cultivation outcome with evaluation criterion

In order to eliminate limitation of cognition, we should synthesize all evaluation value of each expert by weight. Synthesize $k$ grey correlation degree $r_{i o k}\left(L_{i o}, L_{i k}\right)$, and define it as grey imitating degree comparing with the evaluation criterion. Then we can have the formula of subsystem grey imitating degree:

$$
r_{i}=\frac{1}{K} \sum_{k} r_{i k}\left(L_{i o}, L_{i k}\right)
$$

Where variable $k=1,2, \cdots$, are experts $k, i$ is the $i$ subsystem.

All $\left({ }^{r_{i}}\right)$ respectively indicate grey imitating degree of all subsystems of venture enterprise comparing with the evaluation criterion.

If we comprehensively consider all subsystems, we can have the integrated grey imitating degree comparing with integrated evaluation criterion. of venture enterprise. Define:

$$
\begin{aligned}
& r=\sum_{\mathrm{i}} w_{i} \cdot r_{i} \\
& \text { Where } i \text { is subsystem } i \text {. }
\end{aligned}
$$

\section{VENTURE ENTERPRISES FOSTERING OUTCOME ANALYSIS}

Based on imitating degree model, we focus on comparing the subsystems and system with the designed evaluation criterion to analyze the cultivation outcome of venture enterprise. In fact, this analysis also indicates some evidences that how much we have transferred the potential value into practical value entity by fostering venture enterprise. In other words, according to the analysis result, we can learn what we have fostered better, what we have not. Thus, we can efficiently diagnose venture enterprise to 
find advantages and disadvantages, which will give us a guide that what subsystems or factors we should focus on.

\section{A. Grey imitating degree analysis}

Obviously, grey imitating degree $r_{i}^{t}, r^{t}$ have their own ranges $r_{i} \subset[0,1], \quad r \subset[0,1]$, which indicate the conditions of fostering venture enterprise. If $r_{i}, r$ are too small, we have enough reasons to believe it is a mistake that we have over-evaluate venture enterprise as a high value project before investment, and in fact the investment value and potential is low. Therefore we should reconsider evaluating venture enterprise potential or we should give up investment to the venture enterprise.

Suppose we set up a threshold value $r_{0}$ to grey imitating degree $r_{i}, r$.

About the designing of the threshold value, we should comprehensively consider the industry environment, preference degree of venture capitalist to risk, controlling ability and so on.

If we have the threshold value $r_{0}$, we can have the follow analysis.

\section{B. Analysis to subsystems and system}

According to the threshold value, it gives functions:

If $r_{i} \geq r_{0}$, shows subsystem is satisfied, and If $r \geq r_{0}$, shows system is satisfied;

If $r_{i}<r_{0}$, shows subsystem is not satisfied, and If $r<r_{0}$, shows system is not satisfied; then it should be to strengthen cultivation to subsystems and system or give up investment to venture enterprise.

During the analysis process, we should pay more attention to the system. If the system is higher than the threshold value $r_{0}$, while only some subsystem is lower than threshold value $r_{0}$, maybe we should not give up. Maybe this subsystem is not enough to lead to the failure of venture investment, because other subsystems is aiming to a perfect state and so is the system.

\section{CONCLUSIONS AND SUGgESTIONS}

Venture capital is a dynamic and systemic process. As usual venture capitalist evaluates the investment value by some factors like figure 1 and chose the best project to invest.
Next it is needed to foster it. Monitoring the fostering outcome also can follow the same indicator system of evaluating investment value. Therefore evaluating investment value and fostering outcome is a consistent process.

This paper synthesizes the previous research to construct a evaluation indicator system. According to the scientific principle of "know how", using for reference to the evaluation method of investment value, we bring forward a primary analysis frame to monitor fostering outcome. The comparing thought between evaluating criterion and realistic state is the essential start of evaluation. Grey correlation degree is a mathematics tool of integrating all data material. This paper makes full use of the attribute of grey correlation degree to design a compositive evaluation index-growth imitating degree. And this paper also successfully integrate it into a unity the two processes of evaluation before investment and back investment. These are different from the previous research.

Of course the analysis frame has its limitation. In different stage, venture capital has different stage attributes. To differentiate the stage attributes and design the different parameter values and evaluation values, it is a fussy thing. Although synthesizing several experts' evaluation by weight can reduce the limitation of subjective cognition, it is still unavoidable to make some error. Therefore more and furthermore researches are expected.

Author: Yin Linsen, Phd, Vice Professor, Shanghai Finance University, Email: yls80@126.com.

Acknowledge: This research is supported by Innovation Fund of Shanghai Education Commitment, No11YS236; by Fund of Shanghai Nature Science, No 11ZR1424300; and by Fund of Natural Nature Science, No 71202042.

\section{REFERENCE}

[1] Avinash K.Dixit,Robert S.Pindyck . Investment under Uncertainty [M]. MIT Press, 2000:90 102.

[2] Tyebjee,T.T., and Bruno, A.V. A Model of Venture Capital Investment Activity [J]. Management Sci .,1984,30(9):1051 1066

[3] Liu Si-feng, GAO Tina-bang. Theory and Practice of Grey System [J].Science Press,1999, 52 57 (In Chinese)

[4] Can Jian-chun,Wang Yong,and Li Han-lin.The Grey Multi-hierarchy Evaluationt to Investment Risk of Venture Capital [J]. Journal of Engineering Management,2003,17(2) (In Chinese)

[5] Kaplan, S. and Stomberg, P. Financial Contracting Meets the Real Word: An Empirical Analysis of Venture Capital Contracts [J]. Review of Economics Studies, 2003 (70), 281-315 